\title{
Caracterización epidemiológica, clínica y de laboratorio de la meningitis bacteriana en un hospital escuela
}

\author{
Juan Luis Laínez-Mejía ${ }^{1}$, José Lázaro-Molina ${ }^{1,2}$ y Betty Yamileth-Ávila ${ }^{3}$ \\ ${ }^{1}$ Facultad de Ciencias Médicas; ${ }^{2}$ Hospital Escuela Universitario; ${ }^{3}$ Área Clínica, Facultad de Ciencias Médicas. Universidad Nacional Autónoma de \\ Honduras, Honduras.
}

\begin{abstract}
Resumen
Introducción: Alrededor del mundo se estima que hubo más 300,000 muertes por meningitis bacterianas en el año 2010. En Honduras, entre los años 1983 y 1987 se realizó un estudio que valoró la incidencia de la meningitis aguda bacteriana en adultos en el Hospital Escuela Universitario, donde se observaron 76 casos, de los cuales el $75 \%$ se produjeron en hombres. Objetivo: Analizar las características epidemiológicas, clínicas y de laboratorio en pacientes adultos con meningitis bacteriana atendidos en Urgencias del Hospital Escuela Universitario en los años 2012-2015. Material y métodos: Se realizó un estudio descriptivo, retrospectivo y transversal. La muestra constaba de 78 expedientes clínicos. La recolección de datos se obtuvo mediante aplicación de instrumentos, obteniéndose la información de los expedientes clínicos. Resultados: Se observó una prevalencia de 45 casos (58\%) en varones y $33(42 \%)$ en mujeres. La media de edad fue de 53 años, con una mayor frecuencia entre los pacientes con edades comprendidas entre los 40 y 60 años. Los departamentos más afectados fueron Francisco Morazán y Choluteca, con 45 (58\%) y 10 (13\%) casos, respectivamente. Los síntomas y signos más frecuentes fueron: alteración del estado de conciencia (51 casos [65\%]), fiebre (45 casos [58\%]) y cefalea (42 casos [54\%]). Los cultivos positivos reportaron que el $60 \%$ de los casos fueron ocasionados por Streptococcus pneumoniae. Conclusión: La mayoría de los pacientes eran hombres, con una edad promedio de 53 años y en el $60 \%$ de los cultivos positivos se aisló Streptococcus pneumoniae.
\end{abstract}

Palabras claves: Meningitis. Bacteriana. Meningitis neumocócica. Epidemiología. Valores críticos de laboratorio. Honduras.

\section{Epidemiological, clinical and laboratory characterization of bacterial meningitis in school hospital}

\section{Abstract}

Introduction: Around the world, it is estimated that there were over 3,00,000 bacterial meningitis deaths in 2010. In Honduras, a study was carried out between 1983 and 1987 that evaluated the incidence of acute bacterial meningitis in adults at the Hospital Escuela, where 76 cases were observed, of which $75 \%$ were male. Objective: To analyze the epidemiological, clinical and laboratory characteristics in adult patients with bacterial meningitis treated in the emergency service of the University School Hospital in the years 2012-2015. Material and Methods: The sample was 78 clinical records. The data 
Rev Mex Neuroci. 2018;19

collection was obtained through the application of instruments, getting the information of the clinical files. Results: A prevalence of $45(58 \%)$ male cases and 33 (42\%) female cases were observed. The mean age was 53 years, with a higher frequency among patients aged 40-60 years; The most affected departments were Francisco Morazán and Choluteca with 45 $(58 \%)$ and $10(13 \%)$ respectively. The most frequent symptoms and signs have altered the state of consciousness with 51 (65\%) cases, fever with $45(58 \%)$ cases and headache with 42 (54\%) cases. Positive cultures reported that $60 \%$ of the cases were caused by Streptococcus pneumoniae. Conclusion: The highest frequency was of male patients, with a mean age of 53 years and in $60 \%$ of positive cultures S. pneumoniae was isolated.

Key words: Meningitis. Bacterial. Pneumococcal Meningitides. Epidemiology. Laboratory Critical Values. Honduras.

\section{Introducción}

La meningitis es una infección de las membranas meníngeas que cubren el encéfalo y la médula espinal. Sus manifestaciones clínicas podrían no ser específicas, lo que puede complicar el diagnóstico y retrasar el tratamiento adecuado'.

Alrededor del mundo se estima que en el año 2010 se produjeron más de 300,000 muertes por meningitis bacterianas $^{2}$. La tasa de secuelas neurológicas permanentes para esta enfermedad oscila en un rango del 25 al 50\% después de una infección bacteriana, aunque en el caso de la meningitis meningocócica puede llegar a ser mortal en el $50 \%$ de los casos no tratados ${ }^{3}$. En Honduras, las últimas investigaciones datan de las décadas de 1980 y 1990, cuando un primer estudio durante los años 1983-1987 presentó 76 casos de meningitis bacteriana en el Hospital Escuela Universitario ${ }^{4}, y$ otro estudio retrospectivo sobre neuroinfecciones en este mismo hospital reportó que entre los años 1982 y 1986 se encontraron 67 casos de meningitis bacteriana y 42 de meningitis tuberculosa ${ }^{5}$.

Múltiples investigaciones muestran que las bacterias más frecuentes encontradas en pacientes con meningitis bacteriana y que causan el $80 \%$ de los casos de esta enfermedad son: Haemophilus influenzae, Streptococcus pneumoniae, Neisseria meningitidis, Streptococcus del grupo B y Listeria monocytogenes ${ }^{6-8}$. Actualmente Streptococcus pneumoniae es la bacteria más común en pacientes con meningitis bacteriana, especialmente en las meningitis adquiridas en la comunidad y en las meningitis recurrentes, llegando a ser responsable de entre el 40 y $61 \%$ de los casos ${ }^{9-12}$.

Los pacientes mayores de 18 años generalmente presentan signos y síntomas de irritación meníngea e inflamación del parénquima cerebral, similar a los pacientes menores de 18 años $^{13}$. Sin embargo, sólo una minoría de los mayores de 18 años presenta la tríada clínica clásica de fiebre, alteración del estado mental y rigidez del cuello. Un estudio que incluyó a 696 adultos mostró que la mayoría de los pacientes presentaronal menos dos de los cuatro siguientes signos y síntomas: dolor de cabeza, fiebre, rigidez de cuello y alteración del estado mental ${ }^{14,15}$.

El estudio etiológico tradicionalmente se realiza con cultivos bacterianos y con la reacción en cadena de la polimerasa $(\mathrm{PCR})^{16}$. Los cultivos de líquido cefalorraquídeo (LCR) son el gold standard para el diagnóstico, y el tratamiento debe orientarse según esa información. En la meningitis bacteriana se obtienen los siguientes resultados característicos en el estudio de la punción lumbar $(\mathrm{PL})$ : una marcada elevación de los leucocitos (generalmente $>300 / \mathrm{mm}^{3}$ ), con predominio de polimorfonucleares $>70 \%$, junto con un aumento de la proteinorraquia (> $135 \mathrm{mg} / \mathrm{dll}$ ) y disminución de la glucorraquia $(<60 \%$ de la glucemia sanguínea o una proporción $<0.23)^{6,17}$. Existen pruebas complementarias que nos ayudan a fortalecer nuestra sospecha diagnóstica en caso de no haber sido confirmada ${ }^{18}$.

Dado que las bacterias más comunes causantes de la meningitis bacteriana adquirida en la comunidad son S. pneumoniae y N. meningitidis ${ }^{19-21}$, la antibioticoterapia empírica se basa en una cefalosporina de espectro extendido, como ceftriaxona o cefotaxima, aunque se han observado casos de resistencia, por lo que se recomienda combinarla con vancomicina ${ }^{6,22,23}$. La antibioticoterapia debe prolongarse durante 10-14 días y/o hasta 7 días después de la desaparición de la fiebre. En casos menos frecuentes (bacilos gramnegativos, L. monocytogenes y estafilococos) se mantendrá durante 3-4 semanas ${ }^{1}$.

\section{Materiales y métodos}

Se realizó un estudio descriptivo, retrospectivo y transversal en el Hospital Escuela Universitario, ubicado en Tegucigalpa (Francisco Morazán), en el periodo comprendido entre el 1 de enero de 2012 y el 31 de diciembre de 2015. Ingresaron un total 109 casos por meningitis bacteriana, de los cuales se excluyeron 31 expedientes por no cumplir los criterios de inclusión, con lo que se obtuvo una muestra de 78 expedientes clínicos. 


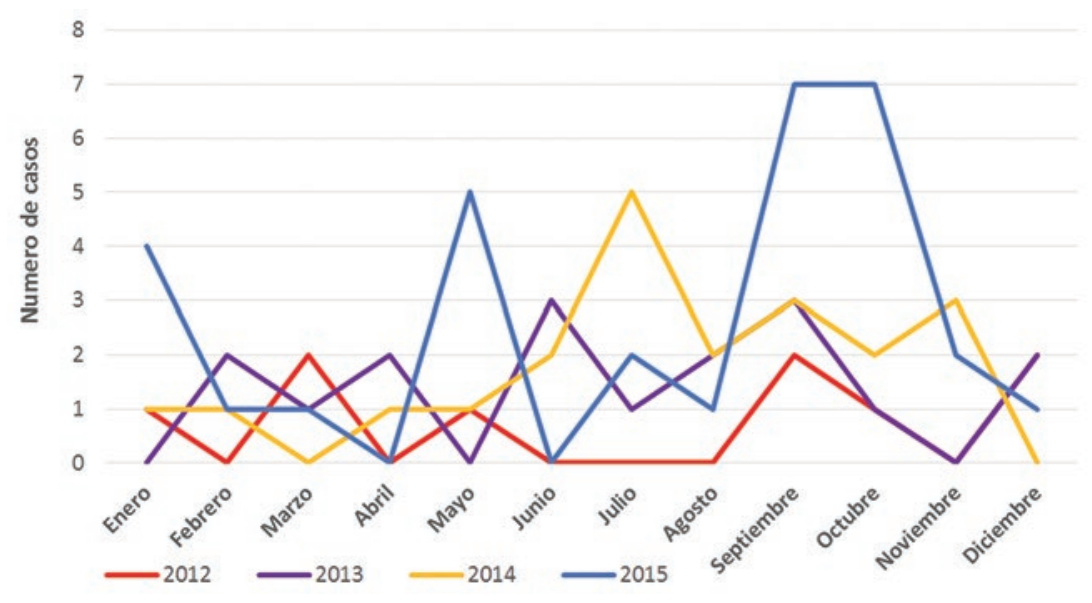

Figura 1. Casos de meningitis bacteriana según mes y año.

Los criterios de inclusión fueron: expediente de paciente con diagnóstico de meningitis bacteriana, sujeto mayor de 18 años de edad, al que se le haya realizado PL y hemograma, y haber sido atendido en urgencias de medicina interna del Hospital Escuela Universitario.

Respecto a los criterios de exclusión, se excluyeron los expedientes de pacientes que no presentaban diagnóstico de meningitis bacteriana, individuos menores de 18 años, enfermos a los que no se les realizó PL o hemograma, o pacientes cuyo expediente clínico no estaba disponible en el Departamento de Archivo.

La recolección de datos se realizó mediante una revisión de expedientes clínicos y la aplicación de un instrumento tipo cuestionario que constó de 22 preguntas abiertas y 14 cerradas. Se realizó la validación del instrumento de recolección de datos por medio de una prueba piloto; se aplicaron 10 cuestionarios para este fin, los cuales fueron incluidos en el número total de la muestra. Se recolectaron: datos generales y sociodemográficos, antecedentes personales patológicos, tiempo de evolución, pruebas de laboratorio y tratamiento.

Previo a la recolección de datos, el protocolo se sometió al Comité de Ética de la Unidad de Investigación Científica de la Universidad Nacional Autónoma de Honduras, y se obtuvo la autorización por parte del Servicio de Neurología del Hospital Escuela Universitario. Se aseguró la confidencialidad y no divulgación de los datos personales consignados en los expedientes clínicos.

La matriz de datos fue construida en el paquete de Microsoft Office Excel $2016^{\circledR}$, el análisis estadístico se realizó con el paquete Epi-Info ${ }^{T M}$, versión 7.2.0.,1 y se estableció una significancia estadística para valores de $\mathrm{p}<0.05$.

\section{Resultados}

La distribución de los 78 casos estudiados mostró que 9 de ellos ocurrieron en el año 2012, 17 en 2013, 21 en 2014 y 31 en 2015 (Fig. 1). Se presentó una prevalencia de 45 casos $(57.7 \%)$ de sexo masculino y 33 $(42.3 \%)$ de sexo femenino. La media de edad fue de 53 años, con una mayor frecuencia entre los pacientes con edades comprendidas entre los 40 y 60 años, que fueron representados por 31 pacientes $(39.7 \%)$, seguidos de 27 pacientes mayores de 60 años (34.6\%) y 20 pacientes entre 18 y 39 años (25.6\%).

Las dos ocupaciones más frecuentes fueron: 25 pacientes mujeres dedicadas a las labores del hogar (32\%) y 16 pacientes de sexo masculino y agricultores (20.5\%). Del total de pacientes, se observó que 27 de ellos (34.6\%) estaban casados, 17 (21.8\%) solteros, $14(18 \%)$ en unión libre, $9(11.5 \%)$ habían enviudado, $1(1.3 \%)$ divorciado y $10(12.8 \%)$ no consignaron su estado civil en el expediente clínico. El estudio también reveló que 42 pacientes (53.8\%) eran alfabetos, $17(21.8 \%)$ analfabetos y $19(24.4 \%)$ no consignaron este dato en el expediente clínico (Tabla 1).

En referencia al área geográfica de donde provenían los pacientes, se pudo constatar que los departamentos con mayor frecuencia fueron: Francisco Morazán (45 [57.7\%]), Choluteca (10 [12.8\%]), El Paraíso y Olancho (5 pacientes cada uno [6.4\%]), Comayagua (4 [5.1\%]) y otros departamentos $(9[11.5 \%])$. De los provenientes de Francisco Morazán ( $n=45)$, se encontró que el Municipio de Distrito Central presentó 30 pacientes $(66.7 \%)$; Talanga, 4 (8.9\%); Reitoca, 3 (6.7\%); Guaimaca, Ojojona y Curaren, $2(4.4 \%)$ cada uno, y Orica y El Porvenir 1 
Rev Mex Neuroci. 2018;19

Tabla 1. Características del paciente con meningitis bacteriana en el Hospital Escuela

\begin{tabular}{|c|c|c|}
\hline Variable & Resultado & Porcentaje \\
\hline Género & Masculino & $57.7 \%$ \\
\hline Edad & 40-60 años & $39.7 \%$ \\
\hline Ocupación & Ama de casa & $32.1 \%$ \\
\hline Estado civil & Casado & $34.6 \%$ \\
\hline Escolaridad & Alfabeto & $53.8 \%$ \\
\hline Departamento de procedencia & Francisco Morazán & $57.7 \%$ \\
\hline Signo/síntoma más frecuente & Alteración del estado de conciencia & $65.4 \%$ \\
\hline Cultivo & Streptococcus pneumoniae & $60.0 \%$ \\
\hline Antibiótico más usado & Ceftriaxona & $88.5 \%$ \\
\hline Duración de la antibioticoterapia & 10 días & \\
\hline \multicolumn{3}{|c|}{ Promedio laboral } \\
\hline Leucocitos & $15.8 \times 103 / \mathrm{ml}$ & \\
\hline Neutrófilos & $81.2 \%$ & \\
\hline Hemoglobina & $13.2 \mathrm{~g} / \mathrm{dl}$ & \\
\hline Citoquímica & Promedio & \\
\hline Celularidad & $687.7 / \mathrm{mm}^{3}$ & \\
\hline Proteínas & $510.6 \mathrm{mg} / \mathrm{dl}$ & \\
\hline Polimorfonucleares & $70.3 \%$ & \\
\hline Glucosa en LCR & $46.1 \mathrm{mg} / \mathrm{dl}$ & \\
\hline Relación glucosa sanguínea/glucosa en LCR & 0.35 & \\
\hline
\end{tabular}

(2.2\%) cada uno. Con respecto al departamento de Choluteca $(n=10)$, resultó con más afectación la Ciudad de Choluteca, con 6 pacientes (60\%), y luego le siguieron los municipios de El Triunfo, Marcovia, San Antonio de Flores y San José, con 1 (10\%) cada uno.

Entre los antecedentes personales más frecuentes de los pacientes se encontraron: hipertensión arterial (30 [38.5\%]), diabetes mellitus (17 [21.8\%]), alcoholismo (16 [20.5\%]), tabaquismo (13 [16.7\%]), cirugías craneales previas (8 [10.2\%]), antecedentes de infección del tracto urinario y epilepsia (7 casos para ambos [9\%]), cardiopatía y evento cerebro vascular (5 cada uno $[6.4 \%])$ y $27(34.6 \%)$ presentaron otras enfermedades (Fig. 2).

Los cuatro signos y síntomas más frecuentes fueron: alteración del estado de conciencia (51 [65.4\%]) -con un promedio en la escala de Glasgow de 12/15-, fiebre
(45 [57.7\%]), cefalea $(42[53.8 \%])$ y signos de irritación meníngea (29 [37.1\%]).

El hemograma de los pacientes de este estudio reveló un promedio de glóbulos blancos de $15.8 \times 10^{3} / \mathrm{ml}$, con un predominio de neutrófilos del 81.2 versus $11.1 \%$ de linfocitos; las células rojas presentaron un promedio de $4.6 \times 10^{6} / \mathrm{ml}$, con un hematocrito promedio de $39.5 \%$ y promedio de plaquetas de $260 \times 10^{3} / \mathrm{ml}$. La citoquímica de la PL reveló los siguientes valores promedio: celularidad, $688 / \mathrm{mm}^{3}$; neutrófilos polimorfonucleares, $70 \%$; mononucleares, 30\%; glucorraquia, $46 \mathrm{mg} / \mathrm{dl}$; relación entre la glucemia y la glucorraquia, 0.35 , y proteínas, $510 \mathrm{mg} / \mathrm{dl}$.

En el momento de la realización de los cultivos de la $\mathrm{PL}$, se obtuvieron como resultados: 3 positivos por Streptococcus pneumoniae (3.8\%), 1 positivo por Klebsiella pneumoniae (1.3\%), 1 por Escherichia coli (1.3\%) y 73 cultivos negativos (93.6\%). 


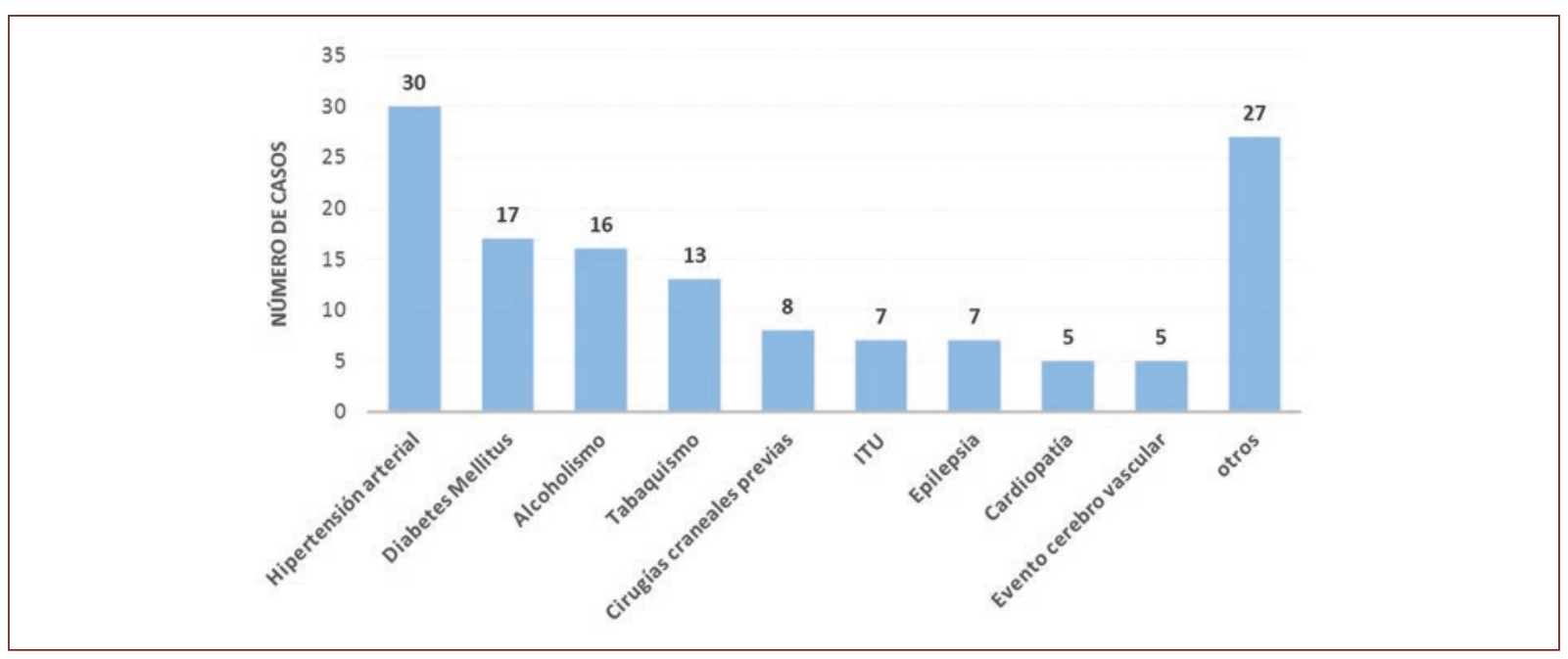

Figura 2. Frecuencia de antecedentes antes de la meningitis bacteriana. ITU: Infecciones del tracto urinario.

En cuanto al tratamiento, este estudio obtuvo como resultado que la ceftriaxona fue el antibiótico más utilizado (69 pacientes [88.5\%]), seguido por vancomicina (57 [73.1\%]), ampicilina (32 [41\%]), penicilina G cristalina $(20[25.6 \%])$, ceftazidima $(5[6.4 \%])$, piperacilina más tazobactam y meropenem ( 3 pacientes cada uno [3.8\%]), y clindamicina e imipenem (1 paciente cada uno [1.3\%]), encontrándose estos fármacos como terapia antibiótica única o combinada.

\section{Discusión}

Las infecciones del sistema nervioso central son un gran reto para los sistemas de salud del mundo, ya que su pronto diagnóstico y su tratamiento adecuado pueden evitar secuelas neurológicas permanentes o incluso la muerte de los pacientes ${ }^{1}$. Con respecto a las principales características sociodemográficas de los pacientes que acudieron a los servicios de urgencias del Hospital Escuela con diagnóstico de meningitis bacteriana, encontramos que, de los 78 pacientes incluidos en este estudio, 29 (37.2\%) fallecieron durante su tratamiento y $49(62.8 \%)$ tuvieron un desenlace favorable. De los 78 pacientes, $45(57.7 \%)$ eran hombres y $33(42.3 \%)$ mujeres, lo cual difiere con lo reportado en los estudios de meningitis bacteriana en EE.UU., donde existe una ligera prevalencia del género femenino $(50.9 \%)$ sobre el masculino $(49.1 \%)^{24}$, o con un estudio realizado en los Países Bajos, donde el género femenino reportó un $50.4 \%{ }^{14}$. Pero un resultado similar a este estudio en Honduras se observó en otro realizado en la ciudad de Guangxi (China), donde se reportó que el $67.9 \%$ de los casos pertenecían al género masculino, siendo más frecuente la meningitis en hombres que en mujeres ${ }^{25}$.

Este estudio $(n=78)$ reveló que en el Hospital Escuela Universitario la edad promedio de los pacientes afectados por meningitis bacteriana fue de 53 años; la mayor cantidad de pacientes se encontró entre los 40 y 60 años (31 casos [39.7\%]), seguidos por 27 pacientes (34.6\%) mayores de 60 años y 20 (25.6\%) entre los 18 y 39 años. Esto se asemeja a lo reportado en otros estudios, en los que los pacientes que se encontraron en edades comprendidas entre los 35 y 65 años fueron el grupo etario más afectado por esta enfermedad 14,24,26.

Respecto a las características sociodemográficas, este estudio ( $n=78$ ) muestra que 42 pacientes $(53.8 \%)$ eran alfabetos, 17 (21.8\%) analfabetos y el resto $19(24.4 \%)$ no reportó en el expediente clínico el grado de escolaridad. Esta prevalencia de los pacientes alfabetos probablemente se debe a que el estudio fue hecho en el Hospital Escuela Universitario, que se encuentra situado en el Municipio de Distrito Central (departamento de Francisco Morazán), donde la tasa de analfabetismo es del $3.9 \%$, según el Instituto Nacional de Estadística ${ }^{27}$. Entre las ocupaciones con mayor frecuencia reportadas tenemos: amas de casa (25 pacientes [32\%]) y agricultores (todos varones) (16 [20.5\%]). También del total de pacientes se obtuvo que 27 (34.6\%) eran casados, 17 (21.8\%) solteros, 14 (18\%) en unión libre, 9 (11.5\%) habían enviudado, 1 (1.3\%) divorciado y 10 (12.8\%) no consignaron su estado civil en el expediente clínico. 
Tabla 2. Comparativa de los valores promedio de citoquímica de la PL y hemograma con los valores registrados en estudios internacionales

\begin{tabular}{|c|c|c|c|c|}
\hline Valor & Honduras & China ${ }^{25}$ & España $^{26}$ & Referencia ${ }^{28}$ \\
\hline \multicolumn{5}{|c|}{ Citoquímica de PL } \\
\hline Celularidad & $687.7 / \mathrm{mm}^{3}$ & $2,540 / \mathrm{mm}^{3}$ & $2,026 / \mathrm{mm}^{3}$ & $10-10,000 / \mathrm{mm}^{3}$ \\
\hline Proteínas & $510.6 \mathrm{mg} / \mathrm{dl}$ & $480 \mathrm{mg} / \mathrm{dl}$ & $463.7 \mathrm{mg} / \mathrm{dl}$ & $>45 \mathrm{mg} / \mathrm{dl}$ \\
\hline Polimorfonucleares & $70.30 \%$ & --- & $90.50 \%$ & $>90 \%$ \\
\hline Mononucleares & $30.10 \%$ & ---- & $9.50 \%$ & $<10 \%$ \\
\hline Glucosa en LCR & $46.1 \mathrm{mg} / \mathrm{dl}$ & $45.0 \mathrm{mg} / \mathrm{dl}$ & $22.2 \mathrm{mg} / \mathrm{dl}$ & $<40 \mathrm{mg} / \mathrm{dl}$ \\
\hline Glucosa sanguínea & $154.6 \mathrm{mg} / \mathrm{dl}$ & ---- & --- & $70-99 \mathrm{mg} / \mathrm{dl}$ \\
\hline Relación de glucosa & 0.35 & --- & 0.14 & $<0.4$ \\
\hline \multicolumn{5}{|c|}{ Hemograma } \\
\hline WBC & $15.8 \times 109 / \mathrm{ml}$ & $11.9 \times 109 / \mathrm{ml}$ & $16.2 \times 109 / \mathrm{ml}$ & --- \\
\hline NEU & $81.20 \%$ & $76.30 \%$ & $80.20 \%$ & --- \\
\hline LYM & $11.20 \%$ & $23.70 \%$ & $19.80 \%$ & --- \\
\hline
\end{tabular}

WBC: Leucocitos; Neutrófilos; LYM: Linfocitos.

Los departamentos que reportaron más casos en este estudio $(n=78)$ fueron: Francisco Morazán (45 casos [57.7\%]), Choluteca (10 [12.8\%]), El Paraíso y Olancho (5 casos cada uno [6.4\%]), coincidiendo con el área geográfica de influencia del Hospital Escuela Universitario. Con respecto a los pacientes provenientes del departamento Francisco Morazán $(n=45)$, se encontró que el lugar de procedencia más frecuente el Municipio de Distrito Central, con 30 casos (66.7\%). Respecto a los casos del departamento de Choluteca ( $n=10)$, Ciudad de Choluteca fue la que reportó la mayor incidencia, con 6 pacientes (60.0\%).

Estudios internacionales han demostrado que los síntomas y signos con los que se presentan los pacientes resultan de gran utilidad para el diagnóstico de la meningitis bacteriana. Actualmente ya no se utiliza la tríada clásica de fiebre, alteración del estado mental y rigidez del cuello para el diagnóstico de la meningitis, ya que sólo se manifiesta en el $44 \%$ de los casos $^{14}$. En este estudio $(n=78)$ se presentaron cuatro signos y síntomas con mayor frecuencia; estos son: alteración del estado de conciencia (51 pacientes [65.4\%]), fiebre (45 casos [57.7\%]), cefalea (42 pacientes [53.8\%]) y signos de irritación meníngea (29 casos [37.1\%]). Un estudio prospectivo internacional sobre las características clínicas y los factores pronósticos en adultos con meningitis bacteriana que incluyó a 696 adultos observó que la mayoría de los pacientes presentaron al menos dos de los cuatro siguientes síntomas y signos: dolor de cabeza, fiebre, rigidez de cuello y alteración del estado mental ${ }^{14,25}$, lo cual concuerda precisamente con los resultados de este estudio realizado en el Hospital Escuela Universitario.

Los análisis de laboratorio para el diagnóstico de la meningitis bacteriana resultan de mucha utilidad, tanto para la confirmación del diagnóstico como, en su defecto, para la sospecha diagnóstica. Aunque el gold standard continúa siendo el cultivo del líquido cefalorraquídeo, nos encontramos con técnicas moleculares como la PCR -que es confirmatoria-, el análisis del hemograma completo, la citoquímica del LCR, la prueba de látex, etc., que nos ayudan a afianzar la sospecha diagnóstica ${ }^{18}$. En este estudio se analizó el hemograma, el cultivo y la citoquímica del LCR, cuyos resultados se muestran y comparan en la tabla 2 con los valores promedios obtenidos en dos estudios distintos y los valores de referencia presentados en el libro $\mathrm{Ha}$ rrison. Principios de medicina interna.

Como se ha mencionado anteriormente, el gold standard como método diagnóstico para la meningitis bacteriana es el cultivo del LCR, que resulta positivo en un $70-85 \%$ de los casos, y éste puede ser auxiliado en caso de ser negativo por métodos moleculares como la PCR $1,6,9,28$; pero este estudio reveló que al $100 \%$ de los pacientes no se les realizó la PCR y que solamente el $6.4 \%$ de los cultivos resultaron positivos, resultado muy similar a lo encontrado en la década de 1990 en este mismo hospital, donde solamente se pudo 
identificar un $14.5 \%$ de cultivos positivos ${ }^{4}$, lo que continúa siendo una tasa por debajo del promedio. Cabe destacar que, a pesar del elevado índice de cultivos negativos, se encontró que en el $60 \%$ de los cultivos positivos se aisló Streptococcus pneumoniae, lo cual concuerda con muchos estudios internacionales, en los que ésta es la bacteria principal causante de la meningitis bacteriana $24-26,29,30$.

En lo que concierne al tratamiento recibido por los pacientes, el $100 \%$ recibió antibioticoterapia combinada con dos fármacos, pero este estudio $(n=78)$ mostró que los antibióticos más frecuentemente utilizados dentro de la terapia combinada fueron: ceftriaxona (69 pacientes [88.5\%]), vancomicina (57 [73.1\%]), ampicilina (32 [41\%]) y penicilina cristalina (20 [25.6\%]), lo cual coincide con los estudios internacionales y el manejo empírico de la meningitis bacteriana, que se basa en el uso de ceftriaxona y vancomicina o, en su defecto, en el empleo de la penicilina cristalina como una alternativa ${ }^{6,9-11}$. Es razonable considerar que estos pacientes recibieron un tratamiento empírico, considerando la baja incidencia de cultivos positivos, pero también es importante tener presente el tiempo promedio que duró dicho tratamiento entre los pacientes no fallecidos ( $n=49$ ), el cual fue de 9.8 días para la ceftriaxona, de 8.7 días con la vancomicina, de 8.4 días con la ampicilina y de 8.7 días con la penicilina cristalina.

Este estudio también reveló que el promedio de estancia intrahospitalaria para los pacientes no fallecidos y diagnosticados con meningitis bacteria en el Hospital Escuela Universitario $(n=49)$ fue de 10 días, lo que representa una leve reducción en comparación al último estudio sobre esta enfermedad realizado en este mismo hospital, donde el $55.3 \%$ de los pacientes necesitó entre 11 y 20 días intrahospitalarios ${ }^{4}$.

\section{Conclusiones}

La incidencia de la meningitis bacteriana fue mayor entre los hombres. El grupo etario más afectado fue el de los pacientes con 40-60 años y la edad promedio fue de 53 años.

Los departamentos que reportaron mayor incidencia en este estudio fueron Francisco Morazán (58\% de los casos) y Choluteca (13\%).

Los síntomas y signos más frecuentes entre los pacientes diagnosticados con meningitis bacteriana fueron, en orden de frecuencia: alteración del estado de conciencia, fiebre, cefalea y signos de irritación meníngea.

Entre los antecedentes más frecuentes en los pacientes con meningitis bacteriana encontramos: hipertensión arterial, diabetes mellitus, alcoholismo y tabaquismo.

En el estudio de la citoquímica del líquido cefalorraquídeo, encontramos una celularidad promedio de 688 células, con un predominio de polimorfonucleares de un $70 \%$, una hiperproteinorraquia de $510 \mathrm{mg} / \mathrm{dl}$ y una glucorraquia de $46 \mathrm{mg} / \mathrm{dl}$, con una relación entre la glucosa sérica y la sanguínea de 0.35 .

Streptococcus pneumoniae fue aislado en el $60 \%$ de los cultivos positivos de líquido cefalorraquídeo, lo que lo convirtió en el mayor causante de meningitis bacteriana.

La terapia antibiótica que se utilizó con mayor frecuencia fue la ceftriaxona ( $89 \%$ de los pacientes), seguida por la vancomicina (73\%) y la ampicilina (42\%). El tiempo promedio de duración de la terapia antibiótica con ceftriaxona fue de 10 días.

\section{Recomendaciones}

Considerando la alta tasa de cultivos negativos de LCR, se debe realizar un estudio prospectivo que analice la razón de la baja incidencia de cultivos positivos en el LCR, que incluya datos como el uso de antibióticos previo a realizar la PL, manejo de la muestra, tiempo que transcurre entre la toma de la muestra y la siembra para cultivos, si se cuenta o no con un manejo apropiado de muestras en los turnos nocturnos, fines de semana y días feriados y, de ser posible, un estudio de control con un laboratorio privado con cultivos de la misma muestra.

Asimismo, conviene tener un protocolo de manejo estandarizado del tratamiento de la meningitis bacteriana basado en las nuevas evidencias, tanto nacionales como internacionales, y de aplicación estricta a nivel nacional.

También sería recomendable elaborar nuevos estudios prospectivos para complementar los alcances de este estudio en el Hospital Escuela Universitario y para caracterizar esta enfermedad en otros hospitales del país, y así conocer de manera más profunda el comportamiento de esta enfermedad a nivel nacional.

Finalmente, convendría realizar evaluaciones posteriores a los pacientes diagnosticados con meningitis bacteriana, considerando que las evidencias internacionales sugieren que entre el 25 y $50 \%$ de los pacientes desarrolla secuelas neurológicas crónicas. Esto ayudaría a mejorar la calidad de vida de estos pacientes y a mejorar su desempeño a nivel laboral y social.

\section{Agradecimientos}

Agradecemos a las autoridades del Hospital Escuela Universitario por brindarnos su ayuda en la 
autorización de la investigación en este centro hospitalario, y al personal de la Unidad de Registro, Archivo y Laboratorio, por brindarnos una atención adecuada y proporcionarnos los expedientes clínicos y base de datos de los análisis de laboratorio necesarios para el desarrollo del presente estudio.

\section{Declaración de conflictos de interés}

Los autores declaran que en este estudio no existen conflictos de interés relevantes.

\section{Fuentes de financiamiento}

No existió una fuente de financiamiento particular para este informe científico.

\section{Bibliografía}

1. Gastón I, Muruzábal J, Quesada P, Maraví E. Infecciones del sistema nervioso central en urgencias. An Sist Sanit Navar. 2008;31 Suppl 1:99-113.

2. Lozano R, Naghavi M, Foreman K, Lim S, Shibuya K, Aboyans V, et al Global and regional mortality from 235 causes of death for 20 age groups in 1990 and 2010: A systematic analysis for the Global Burden of Disease Study 2010. Lancet. 2012;380(9859):2095-128.

3. World Health Organization. Meningitis [citado el 12 de diciembre de 2016]. Disponible en: http://www.who.int/topics/meningitis/es/

4. Bustillo Munguía JP. Meningitis aguda bacteriana del adulto en el bloque médica quirúrgico del Hospital Escuela en los años 1983-1987. Tegucigalpa. 1990. Disponible en: http://www.bvs.hn/cgi-bin/wxis.exe/iah/ scripts/? IsisScript=iah .xis\&lang=es\&base=bimena\&nextAction=Ink\&exprSearch=Juan\%20and\%20Pablo\%20and\%20Bustillo\%20and\%20Mungu \%EDa\&label=Juan\%20and\%20Pablo\%20and\%20Bustillo\%20and\%20 Mungu\%EDa]

5. Polanco Portillo BM, Pineda Estrada EJ. Estudio retrospectivo sobre meningitis bacteriana, tuberculosa, viral y micótica en el bloque médico quirúrgico Hospital Escuela. Enero de 1982 a diciembre de 1986. Tegucigalpa. 1987. Disponible en: http://www.bvs.hn/cgi-bin/wxis.exe/iah/ scripts/?IsisScript=iah.xis\&lang=es\&base=bimena\&nextAction=Ink\&expr Search=Blanca\%20and\%20Miriam\&label=Blanca\%20and\%20Miriam]

6. Brouwer MC, Tunkel AR, van de Beek D. Epidemiology, diagnosis, and antimicrobial treatment of acute bacterial meningitis. Clin Microbiol Rev. 2010;23(3):467-92.

7. Ayala M, Sousa LD, Romano LM, Zorrilla JP, Abut PÁ, Villegas J, et al. Efusión subdural como complicación de meningoencefalitis por Listeria monocytogenes. Neurología Argentina. 2011;3(2):138-9.

8. Mclntyre PB, O'Brien KL, Greenwood B, van de Beek D. Effect of vaccines on bacterial meningitis worldwide. Lancet. 2012;380(9854):1703-11.

9. Garlicki AM, Jawien M, Pancewicz SA, Moniuszko-Malinowska A. Principles of diagnosis and treatment of bacterial purulent meningoencephalitis in adults. Przegl Epidemiol. 2015;69(2):303-7, 415-20.
10. Van de Beek D, Brouwer MC, Thwaites GE, Tunkel AR. Advances in treatment of bacterial meningitis. Lancet. 2012;380(9854):1693-702.

11. McGill F, Heyderman RS, Panagiotou S, Tunkel AR, Solomon T. Acute bacterial meningitis in adults. Lancet. 2016;388(10063):3036:47.

12. Tebruegge $M$, Curtis N. Epidemiology, etiology, pathogenesis, and diagnosis of recurrent bacterial meningitis. Clin Microbiol Rev. 2009;22(1):183.

13. Noguez IC, Melgoza MP, Hernández JAN. Frecuencia de agentes etiológicos identificados en pacientes con meningitis bacteriana aguda. Arch Inv Mat Inf. 2013;5(2):51-5.

14. Van de Beek D, Gans J de, Spanjaard L, Weisfelt M, Reitsma JB, Vermeulen M. Clinical features and prognostic factors in adults with bacterial meningitis. N Engl J Med. 2004;351(18):1849-59.

15. Castro JEL. Meningitis bacteriana y viral. Medicina Legal de Costa Rica. 2016;33(1):234-45.

16. Conca N, Santolaya ME, Farfan MJ, Cofre F, Vergara A, Salazar L, et al. Etiologic diagnosis in meningitis and encephalitis molecular biology techniques. Rev Chil Pediatr. 2016;87(1):24-30.

17. Julián-Jiménez A, Morales-Casado MI. Usefulness of blood and cerebrospinal fluid laboratory testing to predict bacterial meningitis in the emergency department. Neurologia. 2016. pii:S0213-4853(16)30085-8.

18. Brouwer MC, Thwaites GE, Tunkel AR, van de Beek D. Dilemmas in the diagnosis of acute community-acquired bacterial meningitis. Lancet. 2012;380(9854):1684-92.

19. Van de Beek D. Progress and challenges in bacterial meningitis. Lancet. 2012;380(9854):1623-4.

20. Daugla DM, Gami JP, Gamougam K, Naibei N, Mbainadji L, Narbé M, et al. Effect of a serogroup A meningococcal conjugate vaccine (PsA-TT) on serogroup A meningococcal meningitis and carriage in Chad: A community study. Lancet. 2014;383(9911):40-7.

21. Davenport MC, Del Valle, María de la Paz, Gallegos $P$, Kannemann AL Bokser VS. Meningitis bacteriana: factores de riesgo para el desarrollo de complicaciones agudas. Archivos Argentinos de Pediatría. 2007; 105(5):405-10.

22. Hadad P, Gualda A. Bad response to ceftriaxone treatment in Chilean adults with acute bacterial meningitis caused by Streptococcus pneumoniae. Rev Chilena Infectol. 2015;32(3):365-6.

23. Stephens DS, Greenwood B, Brandtzaeg P. Epidemic meningitis, meningococcaemia, and Neisseria meningitidis. Lancet. 2007;369(9580): 2196-210.

24. Thigpen MC, Whitney CG, Messonnier NE, Zell ER, Lynfield R, Hadler JL, et al. Bacterial meningitis in the United States, 1998-2007. N Engl J Med. 2011;364(21):2016-25.

25. Xie Y, Tan Y, Chongsuvivatwong V, Wu X, Bi F, Hadler SC, et al. A Population-Based Acute Meningitis and Encephalitis Syndromes Surveillance in Guangxi, China, May 2007-June 2012. PLoS One. 2015; 10(12):e0144366.

26. Jiménez Caballero PE, Serviá Candela M. Análisis descriptivo de las meningitis por Streptococcus pneumoniae en un hospital terciario. Neurología Argentina. 2012;4(1):6-10.

27. Cruz E. EDUCACIÓN 2016: Instituto Nacional de Estadística Honduras, INE; 2016 [citado el 5 de diciembre de 2016]. Disponible en: http://www. ine.gob.hn/index.php?option=com_content\&view=article\&id=90

28. Longo DL. Harrison. Principios de medicina interna. 18. ${ }^{\text {a }}$ ed. México: McGraw-Hill Interamericana; 2012. Disponible en: https://harrisonmedicina.mhmedical.com/book.aspx?bookid=865]

29. Nkoumou MO, Betha G, Kombila M, Clevenbergh P. Bacterial and mycobacterial meningitis in HIV-positive compared with HIV-negative patients in an internal medicine ward in Libreville, Gabon. J Acquir Immune Defic Syndr. 2003;32(3):345-6. Disponible en: http://journals.Iww.com/ jaids/Citation/2003/03010/Bacterial_and_Mycobacterial_Meningitis_ in.16.aspx

30. Tique V, Alvis N, Parodi R, Bustos A, Mattar S. Meningitis agudas en Córdoba, Colombia 2002-2004. Rev Salud Pública. 2006;8:33-46. 